\title{
Optimization of process parameters in CNC milling for machining P20 steel using NSGA-II
}

\author{
M.Vishnu Vardhan ${ }^{1 *}$, G.Sankaraiah ${ }^{2}$, M. Yohan ${ }^{3}$ \\ ${ }^{1 *}$ Assistant Professor, Mechanical Engineering, Vardhaman college of Engineering, Shamshabad, Hyderabad, India. \\ ${ }^{2}$ Professor, Mechanical Engineering, G Pulla Reddy College of Engineering, Kurnool, Andhra Pradesh, India \\ ${ }^{3}$ Professor, Mechanical Engineering, JNTU College of Engineering, Anantapur, Andhra Pradesh, India
}

\begin{abstract}
In milling process achieving optimal machining condition to enhance the machining efficiency is a complex task. In view of this, the present work proposes an experimental investigation and optimization of machining parameters of CNC milling process on P20 steel work piece. A box-behnken design of Response Surface Methodology (RSM) is used to collect data for the study. Material removal rate (MRR), Tool wear Rate (TWR), Surface roughness $\left(R_{a}\right)$ and Cutting forces are considered as important performance measures which are functions of decision variables viz. cutting speed, feed, and depth of cut. Regression analysis is conducted to relate the performance measures with the decision variables. Finally, a non dominated sorting genetic algorithm (NSGA II) has been proposed for multi objective optimization of the process. The proposed model can be used for selecting ideal process states and enhancing the machining efficiency of milling process.

Keywords: P20 steel, MRR, TWR, Surface roughness, cutting forces, NSGA-II
\end{abstract}

\section{Introduction}

Milling is very important operation in which multi point cutting tool removes the metal from flat work piece. In milling the quality of surface is of great importance in the functional behavior of the milled components. The widely used index of product quality in finish machining process is surface roughness. During the operation, high temperature and forces affect the life of the cutting tool. If cutting tool fails, it will lead to poor surface finish. So, the surface roughness is the very important response to evaluate the cutting performance. Cutting forces and Material removal rate is also the main responses to be considered for evaluating the performance of milling process. The factors affecting the surface roughness are the machining conditions, work piece material and tool geometry.

Therefore in order to obtain the better performance of a milling process, the optimal machining parameters are to be selected. Genetic Algorithm (GA) is the best way to optimize the process parameters. Response surface methodology (RSM) is a collection of mathematical and statistical techniques that are useful for modeling, analysis the process in which response of interest is influenced by several variables. ANOVA is utilized to know the significant parameters influencing the process. Regression analysis is used to relate the process parameters and the responses. Finally a NSGA-II is used to obtain the optimal solution set.

\section{Literature Review}

In the past, ample studies have been attempted until now to enhance the machining efficiency and proficiency of the milling process. However, the key issue is the selection of optimum parameters in such a way that the beneficial attributes like MRR will increase and non beneficial attributes viz. surface roughness, wear rate of cutting tool will decrease leading to enhancement of efficiency of the process. For this issue, various studies reported until now are discussed the paragraphs below. Kadirgama et al. [1] adopted Ant Colony optimization, response surface method and radian basis function network and to optimize the surface roughness in end milling on mould aluminium alloys (AA6061-6). They found that feed rate is the most significant design variable in determining surface roughness as compared to cutting speed, axial depth, and radial depth. Tsao [2] used Grey Taguchi method to optimize the milling process parameters. They observed that the this method is successfully optimized the process parameters by reducing the flank wear from $0.117 \mathrm{~mm}$ to $0.067 \mathrm{~mm}$ and surface roughness by 0.44 microns to 0.24 microns. Liao and Lin [3] studied the milling process of P20 steel with MQL lubrication. The cutting speeds were from $200-500 \mathrm{~m} / \mathrm{min}$ and the feed between $0.1-0.2 \mathrm{~mm} /$ tooth. The authors found that the tool life is higher with MQL, due to an oxide layer formed on the tool inserts that helped to lengthen the tool life. R.A. Ekanayake and P. Mathew[4], investigated the effect of cutting speed, feed and depth of cut on cutting forces with different inserts while milling AISI1020 steel. According to them, the tool offsets and run-outs affect significantly on the cutting forces when it comes to high speed milling, where small cut sections are employed. This can cause uneven wear of the tool tips due to uneven chip loads. Turgut et al. [5] studied the consequence of cutting speed, feed rates and altered cutting tool types (coated and uncoated) on cutting forces and surface roughness in face milling operation. They found that major cutting force $\left(F_{x}\right)$ is increasing with increasing in feed rate and depth of cut whereas it is decreasing with increasing cutting speed. It is observed that good surface quality is obtained with increase in cutting speed for both coated and uncoated tools.

\section{Experimental Work}

The experiments were conducted as per Box-Behnken design of response surface methodology (RSM) because it performs non-sequential experiments having fewer design points. It works in safe operating zone for the process as such a design does not have axial points. On the other hand, central composite designs have axial point outside the cube which may not be in the region of interest or may be impossible to run as they are beyond safe operating zone. Seventeen experimental runs need to be performed in Box-Behnken design with three factors each at three levels and six centre points. It helps to 
estimate a suitable functional relationship between input parameters on output responses. Generally, a second-order model shown in equation is employed in response surface methodology shown in equation (1).

$\mathrm{Y}=\beta_{0}+\sum_{i=1}^{k} \beta_{\mathrm{i}} \mathrm{X}_{\mathrm{i}}+\sum_{i=1}^{k} \beta_{\mathrm{ii}} \mathrm{X}_{\mathrm{i}}^{2}+\sum_{i=1}^{k} \sum_{j=1}^{k} \beta_{\mathrm{ij}} \mathrm{X}_{\mathrm{i}} \mathrm{X}_{\mathrm{j}}+\varepsilon$

Where $\mathrm{Y}$ is the output variable, $\mathrm{X}_{\mathrm{i}}$ 's are input parameters, $\mathrm{X}_{\mathrm{i}}^{2}$ and $\mathrm{X}_{\mathrm{i}} \mathrm{X}_{\mathrm{j}}$ are the square and interaction terms of parameters respectively. $\beta_{0}, \beta_{\mathrm{i}}, \beta_{\mathrm{ii}}$ and $\beta_{\mathrm{ij}}$ are the unknown regression coefficients and $\varepsilon$ is the error.

Experiments has been conducted to investigate the effect of cutting speed, feed, and depth of cut on performance measures viz. MRR, TWR, surface roughness (Ra) and cutting forces. In Response surface methodology (RSM), the parameters cutting speed, feed, and depth of cut are given as input parameters and surface roughness, TWR, MRR, and cutting forces are given as output parameters to find the optimal parameters. The regression model is used for determining the residuals of each individual experimental run.

The experiments are planned using box behnken design in RSM to reduce the number of experiments [6]. The experiments were conducted according to design on CNC end milling machine using tungsten carbide end mill cutters. The three cutting parameters discussed above are selected for the present work. Since the considered factors are multi-level variables and their outcome effects are not linearly related, it has been decided to use three level tests for cutting speed, feed rate, and depth of cut. The tool holder used for milling operation was Kenametal tool holder BT40ER40080M.

The work piece used for the present investigation is P20 mould steel. The effect of cutting speed, feed rate (mm/tooth), and depth of cut (mm) on surface roughness, TWR, cutting forces and MRR were studied. The experiments were conducted using box behnken design.

The machining parameters used and their levels chosen are given in below Table 1.

Table 1. Process parameters used and their levels

\begin{tabular}{|l|l|l|l|}
\hline \multirow{2}{*}{ Control Parameters } & \multicolumn{3}{|c|}{ Levels } \\
\cline { 2 - 4 } & Level 1 & Level 2 & Level 3 \\
\hline Cutting speed & 75 & 85 & 05 \\
\hline Feed & 0.1 & 0.15 & 0.2 \\
\hline Depth of cut & 0.5 & 1 & 1.5 \\
\hline
\end{tabular}

At the time of experimentation, the MRR and TWR are calculated by measuring weight of work piece before and after machining operation. The work piece weight is measured initially and after machining of each experiment by precision weighing machine with accuracy of $0.001 \mathrm{~g}$. The cutting forces are calculated by dynamometer which it is mounted below the work piece in the $\mathrm{CNC}$ milling machine.

Table 2. Experimental table

\begin{tabular}{|l|l|l|l|l|l|l|l|}
\hline S.No & Cutting speed & Feed & Depth of cut & MRR & TWR & $\begin{array}{l}\text { Surface } \\
\text { roughness }\end{array}$ \\
\hline 1 & 85.00 & 0.20 & 0.50 & 50036 & 63.291 & 1.08 \\
\hline 2 & 85.00 & 0.10 & 0.50 & 46643.8 & 65.4 & 0.96 \\
Cutting force \\
\hline 3
\end{tabular}

The surface roughness of all the machined components was measured using Taylor Hobson Surtronic machine. The calculated values were tabulated in the Table 2. Based on the selected data the analysis is conducted using the design expert software. RSM were taken to optimize the results. RSM method provides a simple, systematic, and efficient methodology for the optimization of the cutting parameters compared to other methods.

\section{Results And Discussions}

In Response surface methodology (RSM), the parameters cutting speed, feed, and depth of cut are given as input and MRR, TWR, Surface roughness, and cutting forces are given as output to find the optimal parameters. The optimal results and response in ANOVA for the selected model is shown below.

Table 3. ANOVA for MRR

\begin{tabular}{|l|r|r|r|r|r|r|}
\hline & Sum of & & Mean & F & p-value & \\
\hline Source & Squares & df & Square & Value & Prob > F & \\
\hline Model & $4.120 \mathrm{E}+008$ & 7 & $5.886 \mathrm{E}+007$ & 17.60 & 0.0001 & significant \\
\hline A-Cutting speed & $2.644 \mathrm{E}+008$ & 1 & $2.644 \mathrm{E}+008$ & 79.10 & $<0.0001$ & \\
\hline
\end{tabular}




\begin{tabular}{|l|r|r|r|r|r|r|}
\hline B-feed & $1.142 \mathrm{E}+007$ & 1 & $1.142 \mathrm{E}+007$ & 3.42 & 0.0977 & \\
\hline C-depth of cut & $1.918 \mathrm{E}+007$ & 1 & $1.918 \mathrm{E}+007$ & 5.74 & 0.0402 & \\
\hline $\mathrm{BC}$ & $4.722 \mathrm{E}+006$ & 1 & $4.722 \mathrm{E}+006$ & 1.41 & 0.2651 & \\
\hline $\mathrm{A}^{2}$ & $9.302 \mathrm{E}+006$ & 1 & $9.302 \mathrm{E}+006$ & 2.78 & 0.1297 & \\
\hline $\mathrm{B}^{2}$ & $7.284 \mathrm{E}+007$ & 1 & $7.284 \mathrm{E}+007$ & 21.79 & 0.0012 & \\
\hline $\mathrm{C}^{2}$ & $2.068 \mathrm{E}+007$ & 1 & $2.068 \mathrm{E}+007$ & 6.18 & 0.0346 & \\
\hline Residual & $3.009 \mathrm{E}+007$ & 9 & $3.343 \mathrm{E}+006$ & & & \\
\hline Lack of Fit & $1.729 \mathrm{E}+007$ & 5 & $3.458 \mathrm{E}+006$ & 1.08 & 0.4836 & not significant \\
\hline \multicolumn{1}{r|}{ Pure Error } & $1.280 \mathrm{E}+007$ & 4 & $3.200 \mathrm{E}+006$ & & & \\
\hline Cor Total & $4.421 \mathrm{E}+008$ & 16 & & & & \\
\hline
\end{tabular}

The Model F-value of 17.6 implies the model is significant. There is only a $0.01 \%$ chance that a "Model F-Value" this large could occur due to noise. Values of "Prob > F" less than 0.0500 indicate model terms are significant. In this case A, B, C and square terms B x B, C x C are significant model terms. Values greater than 0.1000 indicate the model terms are not significant. If there are many insignificant model terms (not counting those required to support hierarchy), model reduction may improve your model. The "Pred R-Squared" of 0.6173 is in reasonable agreement with the "Adj R-Squared" of 0.8790 . "Adeq Precision" measures the signal to noise ratio. A ratio greater than 4 is desirable. In this model ratio of 12.904 indicates an adequate signal. This model can be used to navigate the design space.

Table 4. ANOVA for TWR

\begin{tabular}{|c|c|c|c|c|c|c|}
\hline \multirow[t]{2}{*}{ Source } & Sum of & & Mean & $\mathbf{F}$ & p-value & \\
\hline & Squares & df & Square & Value & Prob > F & \\
\hline Model & 1177.14 & 6 & 196.19 & 104.50 & $\begin{array}{l}<0.0001 \\
\end{array}$ & significant \\
\hline A-Cutting speed & 913.63 & 1 & 913.63 & 486.65 & $<0.0001$ & \\
\hline B-feed & 19.89 & 1 & 19.89 & 10.59 & 0.0087 & \\
\hline C-depth of cut & 195.92 & 1 & 195.92 & 104.36 & $<0.0001$ & \\
\hline $\mathrm{AB}$ & 21.22 & 1 & 21.22 & 11.30 & 0.0072 & \\
\hline $\mathrm{A}^{2}$ & 6.87 & 1 & 6.87 & 3.66 & 0.0848 & \\
\hline $\mathrm{B}^{2}$ & 18.28 & 1 & 18.28 & 9.74 & 0.0109 & \\
\hline Residual & 18.77 & 10 & 1.88 & & & \\
\hline Lack of Fit & 15.57 & 6 & 2.60 & 3.24 & 0.1372 & not significant \\
\hline Pure Error & 3.20 & 4 & 0.80 & & & \\
\hline Cor Total & 1195.91 & 16 & & & & \\
\hline
\end{tabular}

The Model F-value of 104.5 implies the model is significant. There is only a $0.02 \%$ chance that a "Model FValue" this large could occur due to noise. Values of "Prob > F" less than 0.0500 indicate model terms are significant. In this case A, B, C and square terms A x A, B x B, and interactions A x B are significant model terms. Values greater than 0.1000 indicate the model terms are not significant. If there are many insignificant model terms (not counting those required to support hierarchy), model reduction may improve your model.The "Pred R-Squared" of 0.9332 is in reasonable agreement with the "Adj R-Squared" of 0.9749. "Adeq Precision" measures the signal to noise ratio. A ratio greater than 4 is desirable. In this model ratio of 35.566 indicates an adequate signal. This model can be used to navigate the design space.

Table 5. ANOVA for Surface roughness

\begin{tabular}{|l|r|r|r|r|r|r|}
\hline \multirow{2}{*}{ Source } & Sum of & & Mean & $\mathbf{F}$ & p-value & \\
\cline { 2 - 8 } & Squares & df & Square & Value & Prob > F & \\
\hline Model & 0.56 & 7 & 0.080 & 21.11 & $<0.0001$ & significant \\
\hline A-Cutting speed & 0.16 & 1 & 0.16 & 41.57 & 0.0001 & \\
\hline B-feed & 0.090 & 1 & 0.090 & 23.94 & 0.0009 & \\
\hline C-depth of cut & 0.18 & 1 & 0.18 & 48.52 & $<0.0001$ & \\
\hline $\mathrm{AB}$ & 0.044 & 1 & 0.044 & 11.69 & 0.0076 & \\
\hline $\mathrm{AC}$ & 0.017 & 1 & 0.017 & 4.48 & 0.0634 & \\
\hline $\mathrm{A}^{2}$ & 0.063 & 1 & 0.063 & 16.65 & 0.0028 & \\
\hline $\mathrm{B}^{2}$ & $5.329 \mathrm{E}-003$ & 1 & $5.329 \mathrm{E}-003$ & 1.41 & 0.2650 & \\
\hline Residual & 0.034 & 9 & $3.772 \mathrm{E}-003$ & & & \\
\hline Lack of Fit & 0.026 & 5 & $5.189 \mathrm{E}-003$ & 2.59 & 0.1883 & not significant \\
\hline Pure Error & $8.000 \mathrm{E}-003$ & 4 & $2.000 \mathrm{E}-003$ & & & \\
\hline Cor Total & 0.59 & 16 & & & & \\
\hline
\end{tabular}

The Model F-value of 21.11 implies the model is significant. There is only a $0.02 \%$ chance that a "Model FValue" this large could occur due to noise. Values of "Prob > F" less than 0.0500 indicate model terms are significant. In this case A, B, C and square terms B x B, C x C are significant model terms. Values greater than 0.1000 indicate the model terms are not significant. If there are many insignificant model terms (not counting those required to support hierarchy), model reduction may improve your model. The "Pred R-Squared" of 0.6741 is in reasonable agreement with the "Adj R-Squared" of 0.898. "Adeq Precision" measures the signal to noise ratio. A ratio greater than 4 is desirable. In this model ratio of 15.211 indicates an adequate signal. This model can be used to navigate the design space.

Table 6. ANOVA for Cutting force

\begin{tabular}{|l|r|r|r|r|r|r|}
\hline \multirow{2}{*}{ Source } & Sum of & & Mean & F & p-value & \\
\cline { 2 - 7 } & Squares & df & Square & Value & Prob $>$ F & \\
\hline Model & 6342.10 & 5 & 1268.42 & 50.12 & $<0.0001$ & significant \\
\hline A-Cutting speed & 4465.13 & 1 & 4465.13 & 176.44 & $<0.0001$ & \\
\hline B-feed & 903.12 & 1 & 903.12 & 35.69 & $<0.0001$ & \\
\hline C-depth of cut & 800.00 & 1 & 800.00 & 31.61 & 0.0002 & \\
\hline
\end{tabular}




\begin{tabular}{|l|r|r|r|r|r|l|}
\hline $\mathrm{AB}$ & 110.25 & 1 & 110.25 & 4.36 & 0.0609 & \\
\hline $\mathrm{A}^{2}$ & 63.60 & 1 & 63.60 & 2.51 & 0.1412 & \\
\hline Residual & 278.38 & 11 & 25.31 & & & \\
\hline Lack of Fit & 198.38 & 7 & 28.34 & 1.42 & 0.3872 & not significant \\
\hline Pure Error & 80.00 & 4 & 20.00 & & & \\
\hline Cor Total & 6620.47 & 16 & & & & \\
\hline
\end{tabular}

The Model F-value of 50.12 implies the model is significant. There is only a $0.01 \%$ chance that a "Model FValue" this large could occur due to noise. Values of "Prob > F" less than 0.0500 indicate model terms are significant. In this case A, B, C and square terms B x B, C x C are significant model terms. Values greater than 0.1000 indicate the model terms are not significant. If there are many insignificant model terms (not counting those required to support hierarchy), model reduction may improve your model. The "Pred R-Squared" of 0.6495 is in reasonable agreement with the "Adj R-Squared" of 0.9651. "Adeq Precision" measures the signal to noise ratio. A ratio greater than 4 is desirable. In this model ratio of 21.365 indicates an adequate signal. This model can be used to navigate the design space. Fig. 1 shows the surface plot of variation in MRR with cutting speed vs depth of cut. From the graph it is clear that MRR is increasing with increase in cutting speed and depth of cut. This is due to the fact that with increase in cutting speed the heat generated in the cutting zone increases, due to high heat the metal gets soften and thus increase in MRR. Fig shows the surface plot of variation in MRR with cutting speed vs feed. From the graph it is clear that with increase in feed, MRR is increasing [7].

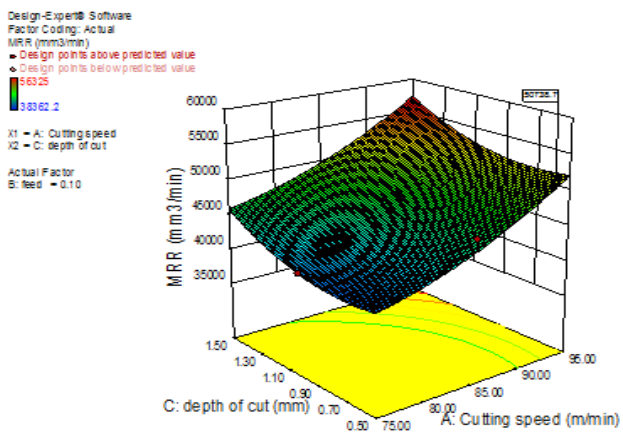

(a)

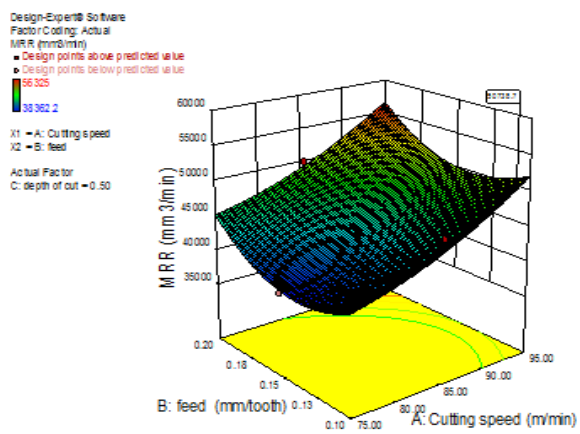

(b)

Figure 1. Surface plots for variation in MRR with (a) cutting speed vs depth of cut (b) cutting speed vs feed

Fig. 2 shows the surface plot of variation in TWR with cutting speed vs feed. It is clear from the graph that increase in cutting speed increases the TWR. Feed is not affecting the TWR in this experiment. Fig. shows the surface plot of variation in TWR with feed and depth of cut. It is seen that with increase in depth of cut, TWR is also increasing. Fig 3. shows the surface plot of variation in Surface roughness with cutting speed vs feed. It is clear from the graph that increase in cutting speed decreases the surface roughness because TWR will be more. Fig shows the surface plot of variation in surface roughness with feed and depth of cut. It is seen that with increase in depth of cut, surface roughness is increasing [8]. Fig 4. shows the surface plot of variation in cutting force with cutting speed vs feed. It is clear from the graph that increases in cutting speed, increases the cutting forces because TWR will be more at higher speeds. Fig shows the surface plot of variation in cutting force with feed and depth of cut. It is seen that with increase in depth of cut and feed, cutting forces are increasing [7].

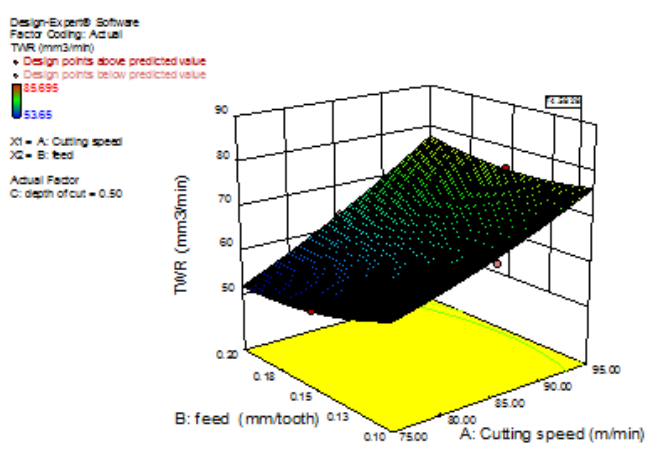

(a)

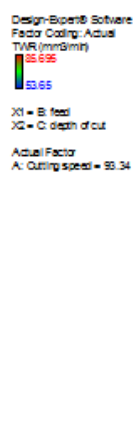

(b)

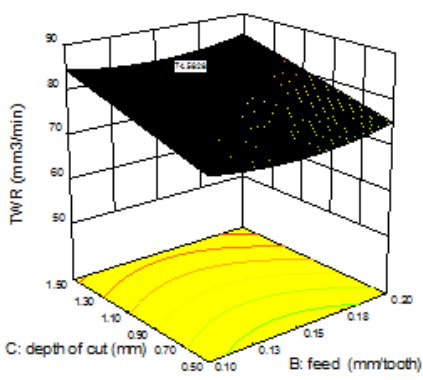

(b)

Figure 2. Surface plots for variation in TWR with (a) cutting speed vs feed (b) feed vs depth of cut 


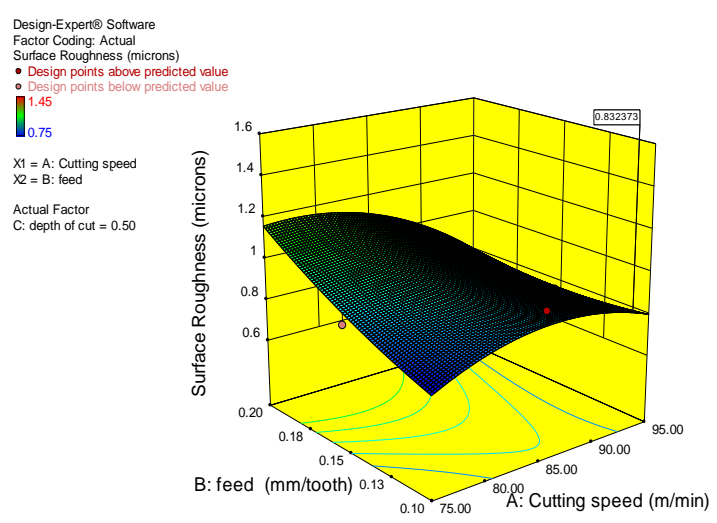

(a)

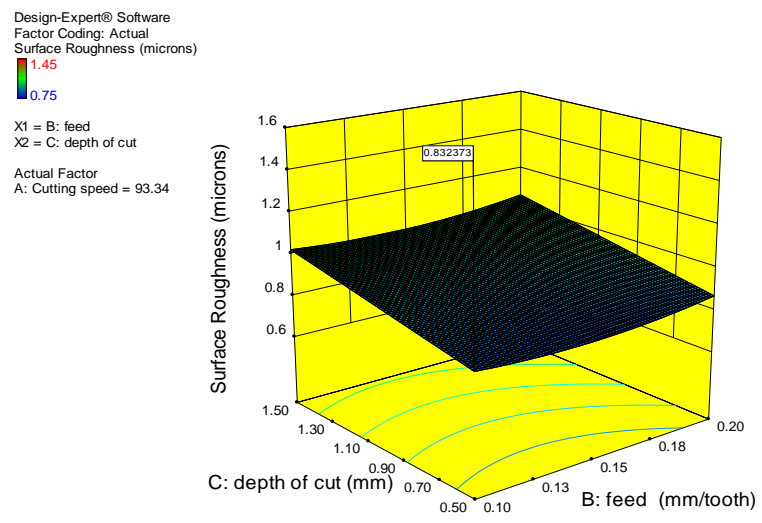

(b)

Figure 3. Surface plots for variation in surface roughness with (a) cutting speed vs feed (b) feed vs depth of cut

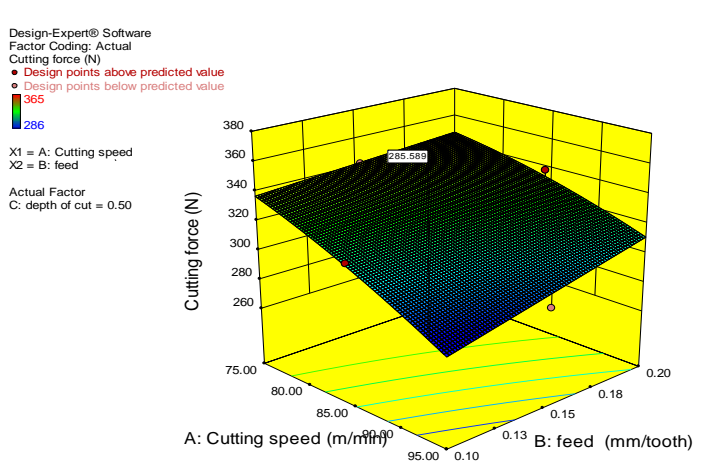

(a)

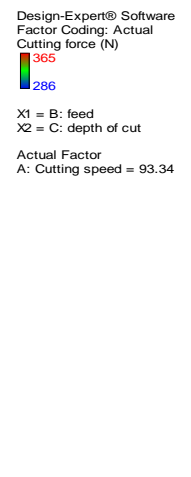

B: feed (mm/tooth)

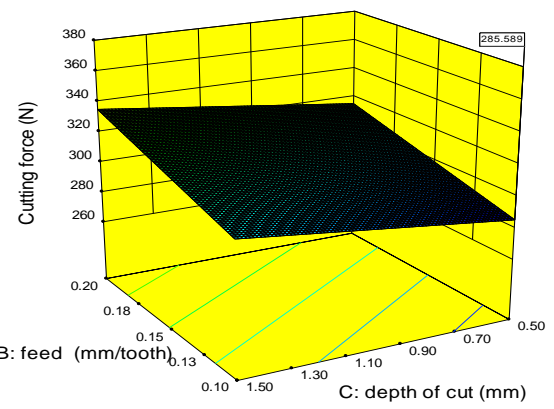

(b)

Figure 4. Surface plots for variation in cutting force with (a) cutting speed vs feed (b) feed vs depth of cut

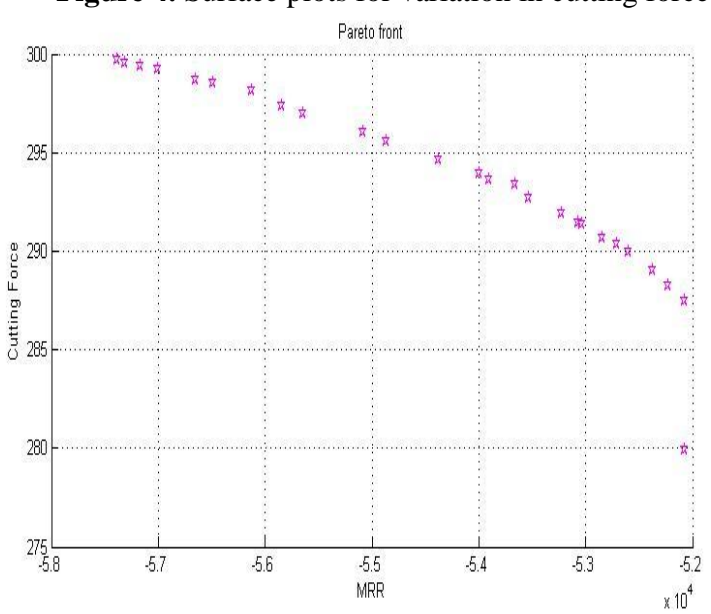

(a)

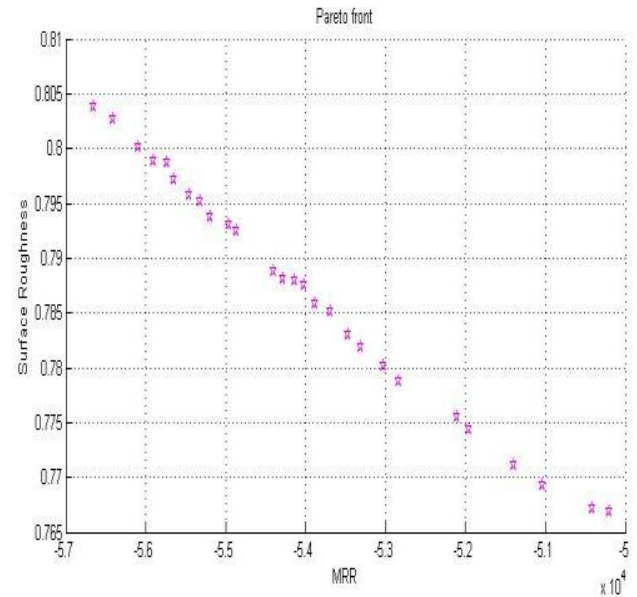

(b) 


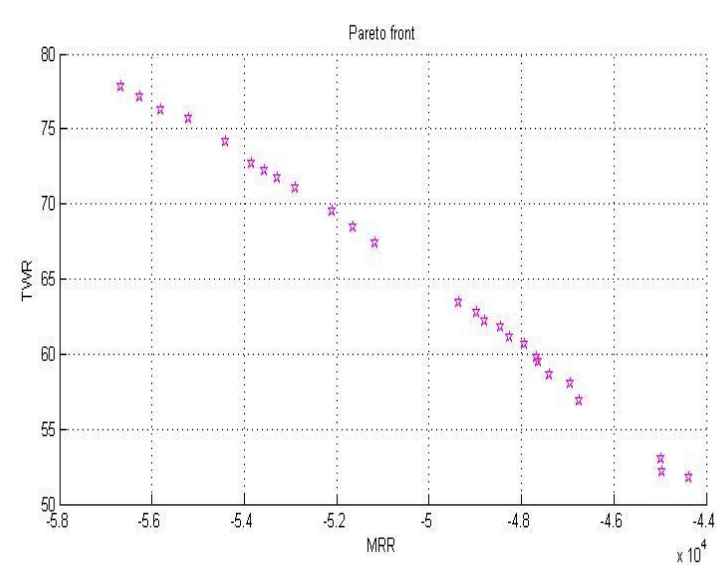

(c)

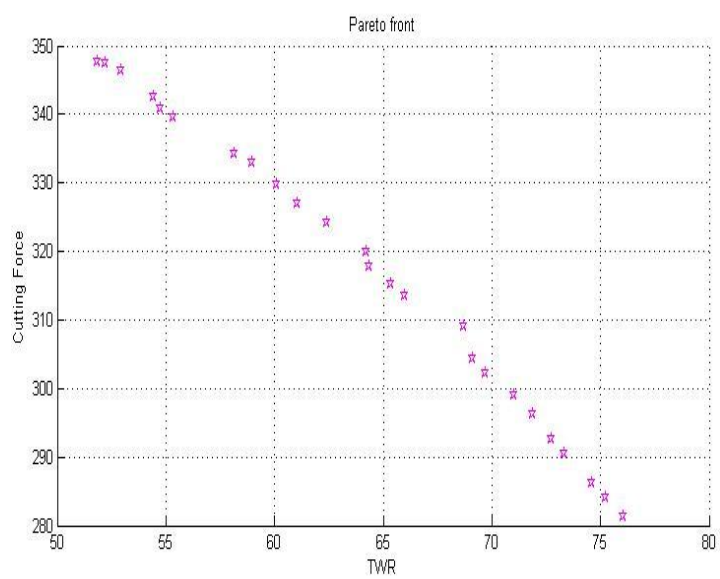

(e)

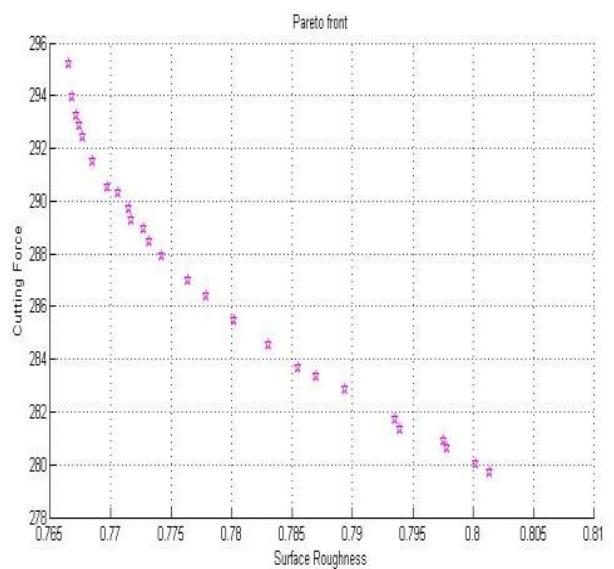

(d)

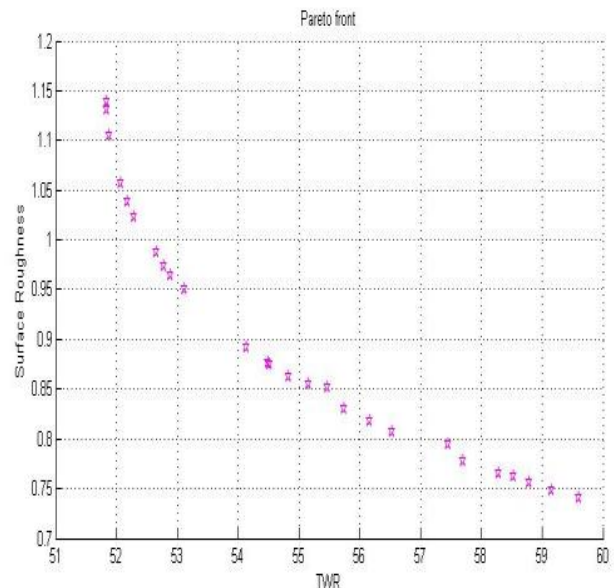

(f)

Figure 5. Pareto front for (a) MRR vs. TWR (b) MRR vs. Surface roughness (c) MRR vs. Cutting force (d) TWR vs Surface roughness (e) TWR vs cutting force (f) Surface roughness vs cutting force

The final equations using ANOVA in terms of actual factors are given below

$\mathrm{MRR}=+1.33980 \mathrm{E}+005-1951.88300 * \mathrm{x}(1)-4.31770 \mathrm{E}+005 * \mathrm{x}(2)-8111.83750 * \mathrm{x}(3)+14.86366 * \mathrm{x}(1)^{\wedge} 2+$

$1.66374 \mathrm{E}+006 * \mathrm{x}(2)^{\wedge} 2+8863.86500 * \mathrm{x}(3)^{\wedge} 2-43459.00000 * \mathrm{x}(2) * \mathrm{x}(3)$

$\mathrm{TWR}=+141.61693-1.79100 * \mathrm{x}(1)-672.76868 * \mathrm{x}(2)+9.89750 * \mathrm{x}(3)+0.012757 * \mathrm{x}(1)^{\wedge} 2+832.27895 * \mathrm{x}(2)^{\wedge} 2+$

$4.60650 * \mathrm{x}(1) * \mathrm{x}(2)$

Surface Roughness $=-10.59240+0.23786 * \mathrm{x}(1)+15.71184 * \mathrm{x}(2)+1.40750 * \mathrm{x}(3)-1.21974 \mathrm{E}-003 * \mathrm{x}(1)^{\wedge} 2+14.21053 *$

$\mathrm{x}(2)^{\wedge} 2-0.21000 * \mathrm{x}(1) * \mathrm{x}(2)-0.013000 * \mathrm{x}(1) * \mathrm{x}(3)$

Cutting force $=+335.84375+2.65000 * \mathrm{x}(1)-680.00000 * \mathrm{x}(2)+20.00000 * \mathrm{x}(3)-0.038750 * \mathrm{x}(1)^{\wedge} 2+10.50000 * \mathrm{x}(1) *$ $\mathrm{x}(2)$

(5)

In this study the goals are maximization of MRR, minimization of TWR, Surface roughness and cutting forces. The relations obtained in Equations (2), (3), (4) and (5) between input parameters and output responses are utilized as functional relations. NSGA II algorithm is used in MATLAB to solve the optimization problems:

Minimize $\{f(x), g(x), h(x), i(x)\}$

Subject to

$75<\mathrm{A}<95$

$0.1<\mathrm{B}<0.2$

$0.5<\mathrm{C}<1.5$

The functions of $\mathrm{f}(\mathrm{x}), \mathrm{g}(\mathrm{x}), \mathrm{h}(\mathrm{x})$ and $\mathrm{i}(\mathrm{x})$ represents the MRR, TWR, Surface roughness and cutting force which are unknown and to be fitted from the experimental values and A, B, C represents cutting force, feed, depth of cut

Table 7. Pareto optimal solutions for MRR vs. TWR

\begin{tabular}{|c|c|c|c|c|c|}
\hline S.No & MRR & TWR & Cutting speed & Feed & Depth of cut \\
\hline 1 & -44376.4 & 51.8 & 75 & 0.196 & 0.5 \\
\hline 2 & -56677.1 & 77.8 & 94.98 & 0.2 & 0.502 \\
\hline 3 & -55197 & 75.7 & 93.7 & 0.198 & 0.504 \\
\hline 4 & -46752.8 & 56.9 & 79.56 & 0.2 & 0.502 \\
\hline
\end{tabular}


Optimization of process parameters in CNC milling for machining P20 steel using NSGA-II

\begin{tabular}{|l|c|c|c|c|c|}
\hline 5 & -44376.4 & 51.8 & 75 & 0.196 & 0.5 \\
\hline 6 & -53576.3 & 72.3 & 91.29 & 0.2 & 0.507 \\
\hline 7 & -55800.6 & 76.3 & 94.02 & 0.2 & 0.503 \\
\hline 8 & -46937.8 & 58 & 80.56 & 0.199 & 0.501 \\
\hline 9 & -49367.7 & 63.4 & 84.88 & 0.199 & 0.503 \\
\hline 10 & -47684.9 & 59.8 & 91.61 & 0.2 & 0.502 \\
\hline 11 & -53843.6 & 72.7 & 83.91 & 0.2 & 0.507 \\
\hline 12 & -48796.7 & 62.2 & 81.07 & 0.198 & 0.502 \\
\hline 13 & -47394.7 & 58.7 & 76.04 & 0.2 & 0.511 \\
\hline 14 & -44976 & 53 & 94.62 & 0.199 & 0.502 \\
\hline 15 & -56267.4 & 77.2 & 82.66 & 0.199 & 0.508 \\
\hline 16 & -47942 & 60.6 & 90.94 & 0.199 & 0.503 \\
\hline 17 & -53289 & 71.7 & 83.14 & 0.2 & 0.502 \\
\hline 18 & -48253.7 & 61.2 & 84.43 & 0.199 & 0.504 \\
\hline 19 & -48962.1 & 62.8 & 87.87 & 0.199 & 0.501 \\
\hline 20 & -51176.8 & 67.4 & 90.55 & 0.199 & 0.503 \\
\hline 21 & -52896.5 & 71.1 & 75.29 & 0.199 & 0.503 \\
\hline 22 & -44962.6 & 52.2 & 88.68 & 0.199 & 0.504 \\
\hline 23 & -51651 & 68.5 & 83.63 & 0.199 & 0.502 \\
\hline 24 & -48459.2 & 61.8 & 89.44 & & 0.502 \\
\hline 25 & -52091.9 & 69.5 & 92.67 & & \\
\hline 26 & -47637 & 74.1 & & & \\
\hline 27 & -54398.4 & & & & \\
\hline
\end{tabular}

At the preliminary stage, a population size of 75 is considered and optimization is carried out. Based on NSGA-II algorithm sorting is done and optimal solution set is generated shown in Table 7. Pareto fronts is drawn shown in Fig.5 to judge in between MRR vs TWR, MRR vs surface roughness, MRR vs cutting force, TWR vs surface roughness, TWR vs cutting force, Surface roughness vs cutting force. These obtained solutions are excellent and any set of process parameters can be taken to obtain the objectives depending upon the machining operations.

\section{Conclusion}

From the analysis of results it can be concluded that

1. Cutting speed, feed rate, and depth of cut are found to be significant for all the responses such as MRR, TWR, surface roughness and Cutting forces.

2. Cutting force is decreasing with increase in cutting speed, and it is increasing with increase in feed rate and depth of cut. MRR is increasing with increase in cutting speed, feed and depth of cut. TWR is increasing with increase in cutting speed, depth of cut. Feed is not affecting the TWR in this case. Surface roughness is decreasing with increase in cutting speed, and it is increasing with increase in feed and depth of cut.

3. Statistical models of MRR, TWR, surface roughness and cutting force are created for subsequent optimization of process parameters as the objective function.

4. Optimal solution set is obtained through optimization of cutting parameters with NSGA-II for better performance of CNC end milling process while machining P20 steel.

\section{References}

[1] K. Kadirgama, M. M. Noor and Ahmed N. Abd Alla , "Response Ant Colony Optimization of End Milling Surface Roughness", Sensors 2010, 10, 2054-2063; doi:10.3390/s100302054.

[2] C. C. Tsao, "Grey-Taguchi method to optimize the milling parameters of aluminium alloy", Int J Adv Manuf Technol (2009) 40:41-48, DOI 10.1007/s00170-007-1314-3.

[3] Y.S. Liao, and H.M. Lin, Mechanism of minimum quantity lubrication in high-speed milling of hardened steel, Int. J. Machine Tools and Manuf., 47(2007) 11, pp.1660-1666.

[4] R.A. Ekanayake and P. Mathew, An Experimental Investigation of High Speed End Milling in Proc. $5^{\text {th }}$ Australasian Congress on Applied Mechanics, ACAM 2007 10-12 December 2007, Brisbane, Australia, pp.1-7.

[5] Turgut Y, Cxinici H, Sxahin I, "Study of cutting force and surface roughness in milling of Al/SiC metal matrix composites" Sci Res Essays 2011; 6(10): 2056-2062.

[6] M.Vishnu Vardhan, G.Sankaraiah, M.Yohan, "Experimental Study of Parameters of P-20 Steel on CNC milling machine using Taguchi's Orthogonal Array”, International Journal of Engineering Technology, Management and Applied Sciences, April 2016, Volume 4, Issue 4, ISSN 2349-4476.

[7] Abou-El-Hossein KA, Kadirgama K, Hamdi, "Prediction of cutting force in end milling operation of modified AISI P20 tool steel" J Mater Process Tech 2007; 182(1-3): 241-247.

[8] Sener Karabulut, "Optimization of surface roughness and cutting force during AA7039/A12O3 metal matrix composites milling using neural networks and Taguchi method", Measurement, Jan 2015, dx.doi.org/10.1016/j.measurement.2015.01.027. 